\title{
Crónica del Festival de Teatro de Dublín 2008
}

\section{Rosana Herrero-Martín}

\author{
Instituto Cervantes, Bremen (Germany)
}

\begin{abstract}
Copyright (c) 2009 by Rosana Herrero-Martín. This text may be archived and redistributed both in electronic form and in hard copy, provided that the author and journal are properly cited and no fee is charged for access.
\end{abstract}

Last edition of the Dublin Theatre Festival (25 Sept. - 12 Oct. 2008) featured a solidly orchestrated programme, full of highlights and stage quality. It was notoriously articulated by a series of proposals, tendencies, or common denominators, which are analysed in this report.

La pasada edición del Festival de Teatro de Dublín, celebrada del 25 de septiembre al 12 de octubre de 2008, se caracterizó por una programación sólidamente estudiada, repleta de aciertos y calidad escénicos, y articulada notoriamente por unas series de propuestas, tendencias, o denominadores comunes, que analizaré a lo largo de esta crónica.

Parte central de la programación correspondió a la serie denominada Off Book, dentro de la cual se incluían adaptaciones escénicas de consagradas piezas literarias no dramáticas a cargo de producciones teatrales irlandesas e internacionales. Dentro de esta serie de relocaciones transgenéricas encontramos propuestas tan singulares $\mathrm{y}$ dispares como Gatz y Heart of Darkness, representaciones literales de siete horas y media y cinco horas y media de duración respectivamente de El gran Gatsby, de F. Scott Fitzgerald, de la compañía estadounidense Elevator Repair Service, y de El corazón de las tinieblas, de Joseph Conrad, one-man show interpretado por el actor irlandés Gavin Kostick; Waves, lectura en clave multimedia de la también experimental novela de Virginia Wolf The Waves, del Teatro Nacional de Gran Bretaña; la transposición musical y ambiental de The Magic Flute de Mozart a un township sudafricano a ritmo de marimbas, tambores y otras percusiones; la fuerza interpretativa de Vanessa Redgrave en el monólogo The Year of Magical Thinking, adaptación teatral de las memorias de Joan Didion (producción también del National Theatre of Great Britain); una laureada versión aérea de Metamorphosis, de Franz Kafka, con elementos del teatro físico y música original de Nick Cave (co-producción Islandia-Reino Unido, Vesturport Theatre y Lyric Hammersmith); First Love, elegante, precisa y ácida versión del relato de Samuel Beckett, a cargo de la compañía irlandesa Gare St. Lazare Players; Delirium, la última obra del joven dramaturgo irlandés Enda Walsh, adaptación libre y desenfrenada de Los hermanos Karamazov, de Fiodor Dostoyevski, con incursiones esperpénticas en géneros tan variopintos como las marionetas, el karaoke, los debates religiosos, y las guerras de familia. Todas ellas son muestras de la impresionante pluralidad que caracteriza intrínsecamente el acto de la lectura, así como de la capacidad de sintonía del teatro para asumir, contar, transformar, y re-imaginar en escena una historia en formato original diferente.

Otra importante vía de exploración por parte de la programación del Festival de Teatro de Dublín 2008 fue sin duda Off Stage, la apuesta por escenarios inusitados que ha propiciado un interesante debate crítico acerca de los desafíos 
y las oportunidades del arte ubicado en espacios desacostumbrados para su género. Tres fueron las producciones que se sacaron fuera del palco de butacas: England, de Tim Crouch, representada en la galería municipal de arte The Hugh Lane; You Are Here, puesta en escena de doble sesión (tarde y noche) separada y complementaria llevada a un apartamento del barrio de moda de la clase especuladora dublinesa, Quartière Bloom (Barrio italiano); y por último, Heart of Darkness, trasladada al número 10 de Ormond Quay, suntuosa casa georgiana coetánea de la atmósfera evocada en el original clásico de Conrad. En los tres proyectos el espacio resulta ser el elemento aglutinador sobre el que se erige el aparato de la historia y sus implicaciones temáticas e interpretativas. Así por ejemplo, en England se exploran los entresijos del arte y el ser humano desde una vertiente transaccional, transmigratoria $\mathrm{y}$ trasplantadora. You Are Here superpone el concepto de casa y hogar al de propiedad en la actual sociedad de catarsis especuladora, y dentro de la cual el espectador se siente mitad voyeur de intimidades caseras, mitad hipotético inversor inmobiliario. Finalmente, la suntuosidad georgiana del domicilio donde se cita a los espectadores de Heart of Darkness provoca no pocos vínculos con los crímenes históricos perpetrados por el imperialismo europeo en África.

Por otra parte, llama poderosamente la atención el protagonismo latente en algunos casos, y patente en otras muchas obras en cartel durante el Festival, del trinomio teatro físico-oralidad-impacto visual. Las producciones irlandesas Dodgems (CoisCéim Dance Theatre) y Circus (Barabbas), herederas de una suprema estirpe irlandesa de verbosidad escénica, son en este sentido exponentes autóctonos del actual impulso físicoidiomático-visual que vive la escena contemporánea. En ambas piezas se transporta al espectador con inusitada inmediatez visual al mundo itinerante del circo (en el caso de Circus) y de las ferias (una pista real de coches de choque constituye el escenario de Dodgems). La inolvidable experiencia teatral que vive el espectador en ambos casos radica en la feliz confluencia de varias dimensiones, como son la viñeta visual, el paisaje sonoro, la virtuosidad acrobática, fabulística y danzarina, que componen unos entramados clásicos de historias locales, universales y míticas, como son la magia del amor y la desolación por la pérdida (Circus); el desarraigo, la soledad y la tolerancia (Dodgems). En este sentido, cabe destacar la novedosa labor de exploración performativa que están llevando a cabo los directores artísticos y coreógrafos de dos compañías de teatro-danza en Irlanda, David Bolger en CoisCéim y Michael Keegan-Dolan en Fabulous Beast (presente en pasadas ediciones del Festival con sus piezas James Son of James, The Bull, Giselle). Si bien están encontrando cierta reticencia por parte de la crítica y del público más tradicionalistas, no se puede negar el nivel de audacia de ambos en la articulación de historias y emociones a través de la amalgama de danza, música, fábula y escenografía. Esta triple entente de teatro físico-oral-visual se desprende así mismo en otras muchas piezas de la programación del Festival, entre otras Metamorphosis (con su transgresora propuesta escenográfica de omisión de la gravedad, dividida en dos niveles, por un lado, el nivel aéreo-acrobático en el que trascurre el drama interior de alienación de Gregor Samsa, y por otro, el nivel a ras de suelo donde se desarrolla el drama familiar); Between the Devil and the Deep Blue Sea (de la compañía británica 1927, deliciosa combinación performativa en la que conviven diversas estéticas modernas como son el cabaret, la animación, el cine mudo, el cómic); While We Were Holding It Together (ingenioso tableau vivant en el que cinco personajes mantienen sus movimientos congelados durante toda la representación, dejando únicamente volar su imaginación, sus percepciones y sus palabras; es una pieza concebida por la coreógrafa y performer croata afincada en Francia Ivana Müller, cuya obra se caracteriza por la exploración de conceptos como la identidad, las normativas sociales y morales, los múltiples filos de la lógica, la percepción y el lenguaje, mediante la interconexión de diversas disciplinas artísticas como la danza, el arte visual, el cine, el texto, y partiendo de fuentes tan dispares como la cultura popular, la filosofía, y las ciencias cognitivas).

Dentro de la programación también se dieron cita diversos exponentes de la escena irlandesa, entre ellos novedades teatrales autóctonas (Rank, de Robert Massey); clásicos contemporáneos (The Cripple of Inishmaan, de 
Martin McDonagh); adaptaciones de autor (Hedda Gabler, de Brian Friel, Delirium, de Enda Walsh); producciones autóctonas de textos internacionales (Cat on a Hot Tin Roof, de Tennessee Williams, a cargo de la compañía The Corn Exchange; Calígula, de Albert Camus, a cargo de la compañía CHRG Theatre); incluso dos producciones beckettianas (Happy Days, coproducción de los Teatros Nacionales de Irlanda y Gran Bretaña, con Fiona Shaw en el papel de Winnie; y First Love, con Conor Lovett, actor curtido en la interpretación de papeles beckettianos). Por otra parte, dentro del ciclo dedicado al teatro contemporáneo latinoamericano, el Pavilion Theatre acogió dos piezas singulares, la producción colombiana It's Only the End of the World (texto original de Jean-Luc Lagarce, a cargo de la compañía A.L.O.D.H.E), y la argentina La omisión de la familia Coleman (escrita y dirigida por Claudio Tocachir, a cargo de la compañía Timbre 4).

Finalmente, dentro de la esmerada programación de Eventos Especiales del Festival, destacaron dos ciclos, In Development y los Paneles de discusión. En el caso de In Development se trataba de una serie de jornadas de puertas abiertas de destacadas compañías teatrales como Pan Pan, The Ark, Rough Magic y Fishamble, en las que el público tuvo acceso gratuito e in situ por primera vez a ensayos, lecturas de ensayo y lecturas semi-dramatizadas de futuros proyectos teatrales, seguidos de puestas en común en las que los espectadores tuvieron la oportunidad de contribuir directamente en el desarrollo de los proyectos. Dentro de los paneles de discusión celebrados caben destacar dos: State of Play, moderado por Vincent dos: State of Play, moderado por Vincent Woods, dramaturgo y presentador del programa de RTÉ Radio 1 "The Arts Show", con la presencia de los directores artísticos de los teatros nacionales de Irlanda, Gran Bretaña, Escocia y Gales (tres de los cuales estuvieron en la programación oficial del pasado Festival), dedicado al papel de los teatros nacionales en el establecimiento de identidad nacional en el actual momento de post-modernidad, post-comunismo, y quién sabe, un inminente post-capitalismo; y Theatre and War, presentado por la actriz Patricia Quinn, en el que, coincidiendo con la puesta en escena en el Festival de la aclamada producción del Teatro Nacional de Escocia, Black Watch, basada en testimonios de soldados escoceses en la Guerra de Irak, los panelistas invitados, entre ellos Fintan O'Toole (escritor, periodista y crítico), Eugene Downes (director de la Agencia Nacional de Cultura de Irlanda, Culture Ireland), tuvieron ocasión de discutir sobre la responsabilidad del arte en tiempos de guerra y sobre la creciente importancia de la diplomacia cultural.

Rosana Herrero-Martín holds a Ph.D. in Irish Theatre (University of Salamanca), a M.A. in Anglo-Irish Literature and Drama (University College Dublin), and a B.A. in English and German Philology (University of Salamanca). She has written the book The Doing of Telling on the Irish Stage: A Study of Language Performativity in Modern and Contemporary Irish Theatre (Frankfurt: Peter Lang, 2008). She is currently freelance Spanish lecturer (Instituto Cervantes, University of Bremen, University of Oldenburg) and literary translator living in Bremen, Germany. Her main areas of interest are theatre, post-colonial literature, literary translation, bilingualism and migration.

\section{Sugerencias Sonoras y Bibliográficas}

Dublin Theatre Festival Reviews, RTÉ Radio 1, The Arts Show, presentado por Vincent Woods:

30 September 2008: http://www.rte.ie/arts/2008/0930/theartsshow.html (You Are Here, Dodgems, Metamorphosis)

2 October 2008: http://www.rte.ie/arts/2008/1002/theartsshow.html (The Year of Magical Thinking, Hedda Gabler, Black Watch, Caligula, Heart of Darkness, Delirium)

7 October 2008: http://www.rte.ie/arts/2008/1007/theartsshow.html (Happy Days, First Love, Rank)

9 October 2008: http://www.rte.ie/arts/2008/1009/theartsshow.html (Waves, Cat on a Hot Tin Roof, It's Only the End of the World

Mulrooney, Deirdre. 2006. Irish Moves: An Illustrated History of Dance and Physical Theatre in Ireland. Dublin: The Liffey Press.

Panel de discusión The State of Play, RTÉ Radio 1, The Arts Show, presentado por Vincent Woods, 6 de octubre 2008. http://www.rte.ie/arts/2008/1006/theartsshow.html 